cellular and muscular structures of the entire left lower limb, but avoiding joints, tendons, and vessels. Had such a burst taken possession of any internal organ I have little doubt it must have proved speedily fatal.

\section{A NOTE ON GOUT.}

BY JAMES EDMUNDS, M.D., M.R.C.P.LoND., Consulting Physician, London Temperance Hospital.

For some years I have discarded sodium salicylate for the potassium salicylate. In doses of ro grs. the potassinm salicylate gives great relief in the acuter cases, and I never see any of the "cardiac depression" which is talked about in connection with the exhibition of potassium salts. The potassium salicylate must be of reliable quality. I always order potassium salicylate (puriss. Hopkin and Williams). If this preparation be used in reasonable frequency of repetition in doses of ro gr., no unfavourable results ensue, the objections'to the sodium salt are obviated, and much better results are obtained. It is most conveniently taken in wafer paper cachets containing 10 grs. exch.

In chronic gout and rheumatism, so long as the urine becomes turbid by the deposition of urates on cooling, I use the old remedy potassium bitartrate. As a febrile drink there is nothing to match it, in barley water nicely made from Robinson's barley flour, and sweetened to tsste with loaf sugar if the patient be of spare habit ; perhaps, also, flavoured with a rab of lemon peel.- Bat the cooking in, or infusion with, lumps of lemon peel spoils the preparation as a pleasan beverage. For the non-febrile chronic cases with turbid or scanty urine I give 20 grs. of the potassium bitartrate as a beverage at lunch or dinner, and sometimes also at bedtime. Twenty grains is a small saltspoonful. It should be put into a drg tumbler and the tumbler then filled up with Salutaris or other pure aërated distilled water. If palatable distilled water be not available the tumbler should be filled up with hot water that has been boiled for a few minutes, so as to make the water safe and throw out chalk. With persons of spare habit the bit of sugar may be added and, if longed for, the flavour of the lemon peel. The bitartrate beverage should be drank as hot tea is drunk. Its use rapidly clears the system of urates. With these two salts I find that I accomplish better than with any other substances all that can be done for the elimination of uric acid. And I find them extremely valuable. Ferric chloride dropped into the urine first throws down all the phosphoric acid as the white ferric phosphate and gives its measure; it then gives the brilliant violet tint which shows how far the system is still charged with salicylic acid, and serves as an end-pointer for the phosphoric acid.

As everyone knows, the potassium bitartrate is the purified argol which is thrown out from grape juice, as the transformation of its sugar into alcohol renders the bitartrate insoluble. It is therefore a pure grape salt, and comes to us with an adequate prestige. But I write purely from the chemical side. The potassium bitartrate gives a pleasant beverage, which is acidulous, and therefore goes well with the gastric juice during digestion. Absorbed as it is directly into the blood by the veins of the stomach, it is carried into the substance of the tissues, and there its tartaric acid is oxydised into $\mathrm{CO}_{2}$ and $\mathrm{H}_{2} \mathrm{O}$, while nascent potassium bicarbonate is set free in the tissues in a state of perfect diffusion and almost infinitesimal dilution. Its use is therefore quite a different thing to the projection into the stomach of a crude alkali. I find that none of the remedies so impudently advertised for uric acid can compete with these very simple and inexpensive ones; 20 grs. of potassium bitartrate contain $5 \mathrm{gr}$. of anhydrous potash $\left(\mathrm{K}_{2} \mathrm{O}\right)$.

As an aperient in such cases $I$ use an old and favourite prescription, which consists of pulv. guaiaci, potass. bitart., sulphur precip. āā $\xi_{j}$, pulv. trag. co. $\xi_{i j}$, m. ft. pulv. A teaspoonful at bedtime in a wineglassful of water or gruel.

Latin-American Scinntific Congress.-The second meeting of the Latin-American Scientific Congress will be held at Montevideo from March 2oth to March 318t, 1901. The work of the Congress will be divided among nine Sections, of which one (the sixth) is assigned to the medical sciences.

\section{MEM ORANDA:}

MEDICAL, SURGICAL, OBSTETRICAL, THERAPEUTICAL, PATHOLOGICAL, Etc.

\section{CASE OF PERSISTENT ADENOIDS IN A MIDDLE.} AGED WOMAN.

Mrs. R., aged 47, came under my observation a few weeks ago at the London Throat Hospital complaining of impaired hearing and difficulty of breathing through the nose. She stated that she had never been able to breathe properly through the nose and presented the typical facial appearance of a chronic mouth breather. On inflation of the middle ears through the Eustachian catheter, both tubes were found to be freely patent and the hearing was improved thereby. On examination with the post-rhinal mirror the post-nasal space was seen to be occupied by a considerable mass, which obscured the upper half of the septum, and extended across the vault from tube to tube. Considering the history, the facial aspect, and the fact that the patient's sister, three years older than herself, had well-marked remnants of what had been presumably:adenoid growths, I formed the opinion that the case was one of adenoid growths which, instead of undergoing the usual process of atrophy, had persisted. I had some hesitation in forming this opinion as one or two cases of post-nasal growth in adults which had lately come under my notice had proved to be malignant. I showed the case at the British Laryngological, Rhinological, and Otological Association, and was supported in my opinion by the majority of the Fellows. One Fellow, however, said that the "local condition was not like adenoids," that "the age of the patient was against adenoids," and gave his opinion that the mass "looked like sarcoma." I removed the growths with forceps, under an anæsthetic, sections from which were kindly examined under the microscope by Dr. Jobson Horne, and pronounced by him to be "adenoid tissue which had undergone changes (inflammatory) covering some length of time." It is interesting, and I think worthy of record, that the patient's hearing in a week or two after the operation considerably improved, and she appreciates in a marked degree the comfort of being able to breathe freely through the nose. Although the age of 47 is considerably below the maximum at which adenoid growths have been found (on referring to the literature, I find that Luc has reported a case at 54, and Solis Cohen one at 70) still $\Upsilon$ am of opinion that cases at this age are sufficiently rarely met with to be worthy of notice. New Cavendish street, $w$.

E. Furniss Potter, M.D.

\section{MAGNESIUM SULPHATE IN DYSENTERY.}

Noting that there has been some cocrespondence in the British Medical Journal regarding the use of magnesium sulphate in dysentery, it may interest your readers to know that when I have had an opportunity of giving it a thorough trial in a large number of cases during the last four years, I have found the treatment of the greatest value in cases of acute dysentery, both in natives of India and in Europeans. I kept records of a large number of cases, and would have submitted these herewith, but unf ( rtunately they were destroyed in the earthquake of 1897 , in which I lost my house and everything in it. I have found that it is seldom of much value in really chronic cases, although I have tried it repeatedly in many instances. The prescription $I$ am in the habit of giving is: Magnesium sulphate (a saturated solution) $3 \mathrm{j}$, dilute sulphuric acid $m x$, in water ; to be given every two hours until the motions have become copious, fæculent, and free from blood and mucous. Gaubati, Assam.

J. L. DICKIE, M.B. Medical Officer, Assam-Bengal Railway.

\section{CERTAIN USES OF COLLODION.}

In the British Medical Journal of November 21st, 1896, I called attention to the value of collodion in the treatment of pruritus ani, in which, I believe, it is always effective, at least temporarily.

In the after-trealment of mosquito bites I have found no application so satisfactory as that of collodion. A dewdrop of contractile collodion is spread on the raised red bite. The itching at once disappears, and with the contraction of the 